\title{
Development of an indirect immunofluorescence assay for PCV3 antibody detection based on capsid protein
}

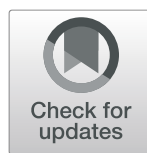

Lun Yao ${ }^{1,2,3 \dagger}$, Chang Li ${ }^{1,2,3 \dagger}$, Junwei Wang ${ }^{2,3}$, Yufang Cheng ${ }^{2,3}$, Ahmed H. Ghonaim ${ }^{2,3}$, Qi Sun ${ }^{2,3}$, Xuexiang Yu ${ }^{2,3}$, Weijie Niu ${ }^{2,3}$, Shengxian Fan ${ }^{2,3}$ and Qigai He $\mathrm{e}^{1,2,3^{*}}$

\begin{abstract}
Porcine circovirus type 3 (PCV3) is a novel porcine circovirus associated with porcine dermatitis and nephritis syndrome (PDNS), reproductive failure, and multisystemic inflammation. Capsid protein (Cap) encoded by PCV3 ORF2 gene has been identified as an immunogenic protein. Currently, there is no immunofluorescence assay (IFA) available for serological diagnosis. Here, the N-terminal 33 amino acids of Cap protein were predicted to serve as a PCV3 nuclear localization signal (NLS). Two types of recombinant plasmids were constructed for recombinant protein expression in Sf9 cells by using a baculovirus expression system: plasmid rvBac-Pc for full-length Cap protein expression and rvBac-Sc for Cap protein expression with a honeybee melittin signal peptide in place of the predicted NLS sequence. Expression of the nuclear localization sequences was further analyzed by IFA. Strong and specific fluorescence signals were observed in the nucleus of rvBac-Pc-transfected cells and in the cytoplasm of rvBac-Sc-transfected cells. No cross-reactivity was observed with porcine circovirus type 2, porcine pseudorabies virus, classical swine fever virus, or porcine reproductive and respiratory syndrome virus. In summary, we developed two fluorescence detection modes for Cap protein that can be used to detect PCV3 antibodies. This method is suitable for the diagnosis and epidemiological investigation of PCV3. This study provides a reliable detection method for monitoring PCV3 antibody level in pigs in the future.
\end{abstract}

Keywords: PCV3, Capsid protein, Antibodies, IFA

\section{Development of a fluorescence method to detect PCV3 antibodies is necessary}

A novel porcine circovirus (PCV) from pig tissues with porcine dermatitis and nephritis syndrome (PDNS) was identified by high-throughput sequencing technology and was designated porcine circovirus type 3 (PCV3) in previous studies (Palinski et al. 2017; Saraiva et al. 2018; Kedkovid et al. 2018). PCV3 infection causes PDNS-like symptoms, reproductive failure, myocarditis, multisystemic inflammation, and congenital tremors in pigs (Palinski et al. 2017; Phan et al. 2016; Ku et al. 2017; Chen et al. 2017; Jiang et al. 2018). It has been reported

\footnotetext{
* Correspondence: he628@mail.hzau.edu.cn

'Lun Yao and Chang Li contributed equally to this work.

'State Key Laboratory of Agricultural Microbiology, Huazhong Agricultural

University, Wuhan, China

${ }^{2}$ The Cooperative Innovation Center for Sustainable Pig Production,

Huazhong Agricultural University, Wuhan, China

Full list of author information is available at the end of the article
}

(C) The Author(s). 2021 Open Access This article is licensed under a Creative Commons Attribution 4.0 International License, which permits use, sharing, adaptation, distribution and reproduction in any medium or format, as long as you give appropriate credit to the original author(s) and the source, provide a link to the Creative Commons licence, and indicate if changes were made. The images or other third party material in this article are included in the article's Creative Commons licence, unless indicated otherwise in a credit line to the material. If material is not included in the article's Creative Commons licence and your intended use is not permitted by statutory regulation or exceeds the permitted use, you will need to obtain permission directly from the copyright holder. To view a copy of this licence, visit http://creativecommons.org/licenses/by/4.0/ The Creative Commons Public Domain Dedication waiver (http://creativecommons.org/publicdomain/zero/1.0/) applies to the data made available in this article, unless otherwise stated in a credit line to the data. 
that PCV3 is widely spread in pig farms in China (Wen et al. 2018; Zheng et al. 2017). It not only poses a huge threat to the pig industry but also brings certain biosafety risks to companion animals and humans (Zhang et al. 2018; Guo et al. 2020; Kedkovid et al. 2018). Hence, it is of great significance to establish an effective antibody detection method for PCV3.

Currently, the most commonly used methods for PCV3 detection in pigs include polymerase chain reaction (PCR) and ELISA (enzyme-linked immunosorbent assay, Yuan et al. 2020; Zhang et al. 2019). ELISA has been used to test for positive porcine serum samples (Deng et al. 2018; Xu et al. 2018) while PCV3-Cap protein-based indirect ELISA is the only method for PCV3 antibody detection (Deng et al. 2018). However, nonspecific binding in ELISA often gives false positive results. In addition, it is difficult to interpret ELISA results when the serum antibody titer is near the cutoff threshold. Compared with PCR and ELISA, IFA (immunofluorescence assay) can be utilized to visualize the localization of viral antigens inside cells, to detect viral antibodies in serum, and to investigate viral infection processes due to its accuracy and high specificity (Koh et al. 2010; Taber et al. 1976). Moreover, semiquantitative IFA analysis of antibody level in serum can also be performed based on fluorescence intensity. The aim of this work was to develop a rapid, easy-to-use and inexpensive Cap protein-based serological diagnostic assay for PCV3 detection.

\section{Verification of baculovirus-expressed PCV3 Cap proteins}

A previous study established indirect IFA to detect PCV2 serum antibodies by cloning PCV2 ORF2 gene into the eukaryotic expression vector $\mathrm{pCEP} 5$, and results were determined by observing the presence or absence of a green fluorescence signal in nucleus or perinucleus (Racine et al. 2004). In this study, pFastBac1 vector was used as backbone to construct two vectors, one containing full-length ORF2 and the other containing ORF2 with a deletion of NLS (nuclear localization signal). To express PCV3 Cap protein in Sf9 cells, they were transfected with rvBac-Sc, rvBac-Pc and wild-type baculovirus rBacmid. After 96 h of transfection, compared with mock-transfected Sf9 cells, transfected cells were enlarged approximately 2fold and showed extensive cellular vacuolation (Fig. 1a).

To increase viral titers of the recombinant baculoviruses, P1 viruses were passaged three times in Sf9 cells. The expression of Cap proteins was analyzed by western blot using a PCV3 Cap-specific monoclonal antibody (Li et al. 2018). Positive Cap protein signals between $23 \mathrm{kDa}$ and $30 \mathrm{kDa}$ were observed in the supernatant and lysate of rvBac-Sc-infected cells and in the lysate of rvBac-Pcinfected cells. Cap protein didn't detected in the lysates of noninfected Sf9 cells, indicating specific Cap expression in Cap-Bac-infected cells (Fig. 1b). Furthermore, cells infected with $\mathrm{P} 4$ generation of recombinant baculoviruses were further analyzed by IFA. rvBac-Sc and rvBac-Pc produced green fluorescence in different localizations inside cells. Intense and specific fluorescence was observed in nucleus and perinuclear regions of rvBac-Pc-infected Sf9 cells, whereas luorescence signal of rvBac-Sc-infected $\mathrm{Sf} 9$ cells was mainly distributed in cytoplasm (Fig. 1c), suggesting that the N-terminal 33 amino acid sequence indeed functions as an NLS.

\section{Optimal number of Sf9 cells and dilution of serum}

The optimal number of Sf9 cells and the optimal serum dilution rate were further determined. Results were classified into,,,-++++++ , or ++++ according to the number of positive cells and fluorescence intensity, as showED in Table 1. At a 200x magnification, the average number of positive cells was determined in five random fields. If no positive cells could be observed, results were identified as "-". If the average number of positive cells was less than 5 , results were identified as " + ". If the average number of positive cells was more than 5 but less than 25 , the results were identified as "++", more than 25 but less than 100 cells were identified as " +++ "and more than 100 cells were identified as "++++". When cell number was $1.0 \times 10^{4} /$ well, a specific but very weak fluorescence signal was observed, which may be due to the cell number being too low. When the number of cells increased to $4.0 \times 10^{4} /$ well or $8.0 \times 10^{4} /$ well, cells were too crowded, and fluorescence overlapped frequently, resulting in inconvenience in observation. When serum was diluted to $1: 10$ or $1: 20$, positive cells exhibited a bright specific fluorescence signal. However, when serum was diluted to $1: 40$, only a weak green fluorescence signal was observed in cytoplasm of rvBac-Sc-infected Sf9 cells. In summary, the optimal cell number per well was $2.0 \times 10^{4} /$ well, and the optimal serum dilution was 1:20 (Table 1).

\section{Judgment of a positive serum sample}

As the cutoff of results is subjective, operator needs to have a wealth of experience to minimize the interference of visual errors (Demir et al. 2020). Furthermore, some pig farms may have been immunized with subunit vaccines originating from the baculovirus expression system, resulting in the production of nonspecific antibodies in the serum, in turn causing a nonspecific green fluorescence signal and 


\section{a}
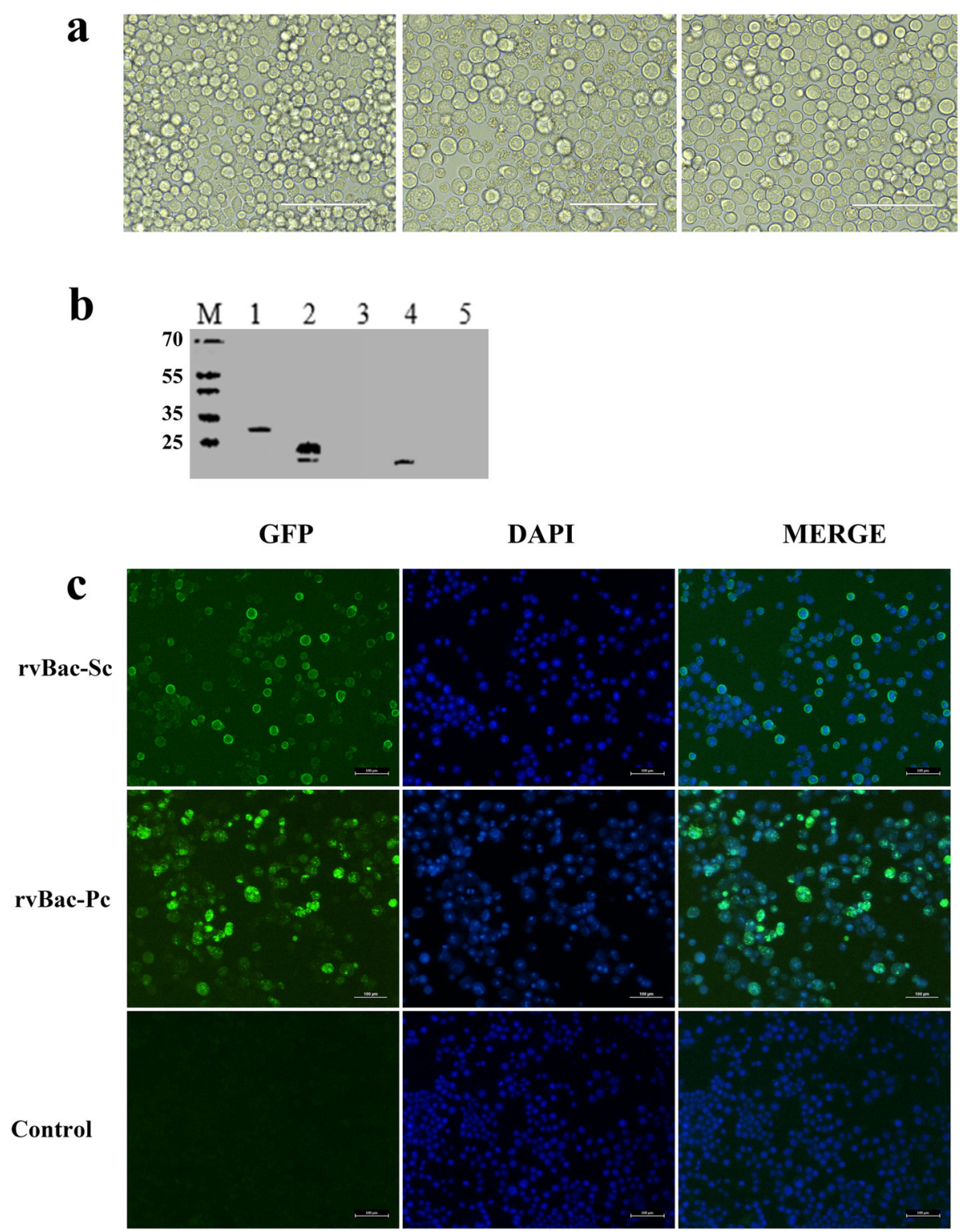

Fig. 1 Verification of PCV3 Cap protein expression in Sf9 cells. a Cytopathic effect in Sf9 insect cells transfected with recombinant bacmids. The left panel shows Sf9 cells, the middle panel shows Sf9 cells transfected with rvBac-Sc, and the right panel shows rvBac-Pc-transfected Sf9 cells. $\mathbf{b}$ Identification of recombinant Cap protein expression by western blot. Lane 1, cell lysate of Sf9 cells infected with rvBac-Pc. Lane 2, cell lysate of rvBac-Sc-infected Sf9 cells. Lane 3, supernatant of rvBac-Pc-infected Sf9 cells. Lane 4, supernatant of Sf9 cells infected with rvBac-Sc. Lane 5, cell lysate of mock-infected Sf9 cells. M, Marker. c Identification and localization of PCV3 Cap protein in infected Sf9 cells by IFA. rvBac-Sc, Sf9 cells infected with rvBac-Sc. rvBac-Pc, Sf9 cells infected with rvBac-Pc. Con, mock-infected Sf9 cells

affecting the accuracy of this assay. To reduce the influence of subjective judgment error and nonspecific green fluorescence signals, serum was separately added to rvBac-Sc-infected and rvBac-Pc-infected Sf9 cells. Sf 9 cells infected with rvBac-Sc exhibited green fluorescence in cytoplasm, while Sf9 cells infected with rvBac-Pc displayed green fluorescence in nucleus. Only when the correct green fluorescence pattern was observed in both types of infected cells could the sample be judged as PCV3-positive.

\section{Detection limitation and cross-reactivity of the IFA method}

Cap protein encoded by PCV3 ORF2 shares only $21 \%$ and $36 \%$ homology with the corresponding proteins in PCV1 and PCV2, respectively. They exhibit low amino acid homology with no cross-reactivity (Woźniak et al. 2019). Here, PCV3-positive serum from a natural PCV3 infection was diluted to 1:10, 1:20, 1:40, 1:80, 1:160, 1: 320, 1:640, 1:1280 and 1:2560 and tested by IFA on Sf9 cells infected with rvBac-Sc, rvBac-Pc and rvBac, as 
Table 1 Fluorescent observations of different treatments

\begin{tabular}{|c|c|c|c|}
\hline Analysis & & Specific fluorescence & Nonspecific fluorescence \\
\hline \multirow[t]{4}{*}{ Cell number $\left(10^{4} /\right.$ well) } & 1.0 & ++ & - \\
\hline & 2.0 & ++++ & - \\
\hline & 4.0 & ++++ & - \\
\hline & 8.0 & ++++ & - \\
\hline \multirow[t]{5}{*}{ Serum dilution } & $1: 10$ & ++++ & - \\
\hline & $1: 20$ & ++++ & - \\
\hline & $1: 40$ & +++ & - \\
\hline & $1: 80$ & ++ & - \\
\hline & $1: 160$ & + & - \\
\hline \multirow[t]{5}{*}{ Cross-reactivity of pathogens } & PCV3 & ++++ & - \\
\hline & PCV2 & - & - \\
\hline & PRV & - & - \\
\hline & CSFV & - & - \\
\hline & PRRSV & - & - \\
\hline
\end{tabular}

PCV3 Porcine circovirus type 3, PCV2 Porcine circovirus type 3, PRV pseudorabies virus, CSFV classical swine fever virus, PRRSV porcine reproductive and respiratory syndrome virus. Results are classified as,,,-++++++ , or ++++ according to the number of positive cells and the intensity of fluorescence

described in the Methods section. When the serum of PCV3 was diluted 640-fold, a weak fluorescence signal was still present in both of rvBac-Sc- and rvBac-Pcinfected cells (Fig. 2). However, when the serum was diluted 1280-fold, no detectable green fluorescence signal was observed. No positive signal was observed by using this IFA method to detect PCV2- (Fig. 2), PRV (pseudorabies virus)-, CSFV-(classical swine fever virus), or PRRSV (porcine reproductive and respiratory syndrome virus)-positive serum (Table 1), suggesting that this assay has good specificity. Then, three positive and one negative PCV3 Cap serum samples were tested by IFA with different batches of rvBac-Sc-, rvBac-Pc- and rvBacinfected Sf9 cells, and no obvious changes in fluorescence intensity were observed, suggesting that this assay has good reproducibility.

In addition, the immobilization of specimens is an important step in indirect IFA. During immobilization, it is also important to maintain the antigenicity of antigens while preserving their localization inside cells. After many trials, absolute ethanol was selected as a fixative due to its excellent characteristics in maintaining cell morphology and specific fluorescence. Results of repeatability test showed that there was no obvious difference in green fluorescence intensity produced by different batches of cells (data not shown), indicating that this method has good repeatability. In summary, the method established in this research showed good specificity and reproducibility.

\section{Comparison of ELISA and IFA}

The robustness of IFA was further evaluated with field samples. A total of 102 serum samples were randomly selected for IFA and ELISA tests. Comparing IFA with ELISA, 46/ 49 (93.88\%) ELISA-positive samples tested positive by IFA. Similarly, of the field samples originally testing negative by ELISA, 53/53 (100\%) were negative by IFA (Table 2). The chi square test was performed to assess the correlation between these two methods, which was found to be significant, with the results reflecting the same index.

\section{Epidemiological investigation of PCV3 antibody in China}

Since PCV3 was first reported in the United States in 2015, China, South Korea, Poland, Brazil, Japan and other countries have also reported, and its prevalence rate in various countries has increased year by year. The genome sequences of PCV3 from different countries are quite similar, suggesting that PCV3 may spread across borders (Palinski et al. 2017; Kwon et al. 2017; Ku et al. 2017). Currently, the only detection method for PCV3 antibody is PCV3-Cap protein-based indirect ELISA (Deng et al. 2018). However, ELISA often shows false positive results. In addition, insufficient antigen purity often results in difficulty in distinguishing results near the negative-positive thresholds. Therefore, the goal of this study was to establish a low-cost, easy-to-use, sensitive and specific method for detecting PCV3 antibodies and to perform an epidemiological investigation of PCV3 antibodies in China.

Here, epidemiological investigation of PCV3 was performed by using this IFA method. The results showed that the positive rate of PCV3 antibody was $45.8 \%$ (143/ 312). Detection rates of PCV3 antibody were further categorized corresponding to the growth stage of pigs, and 


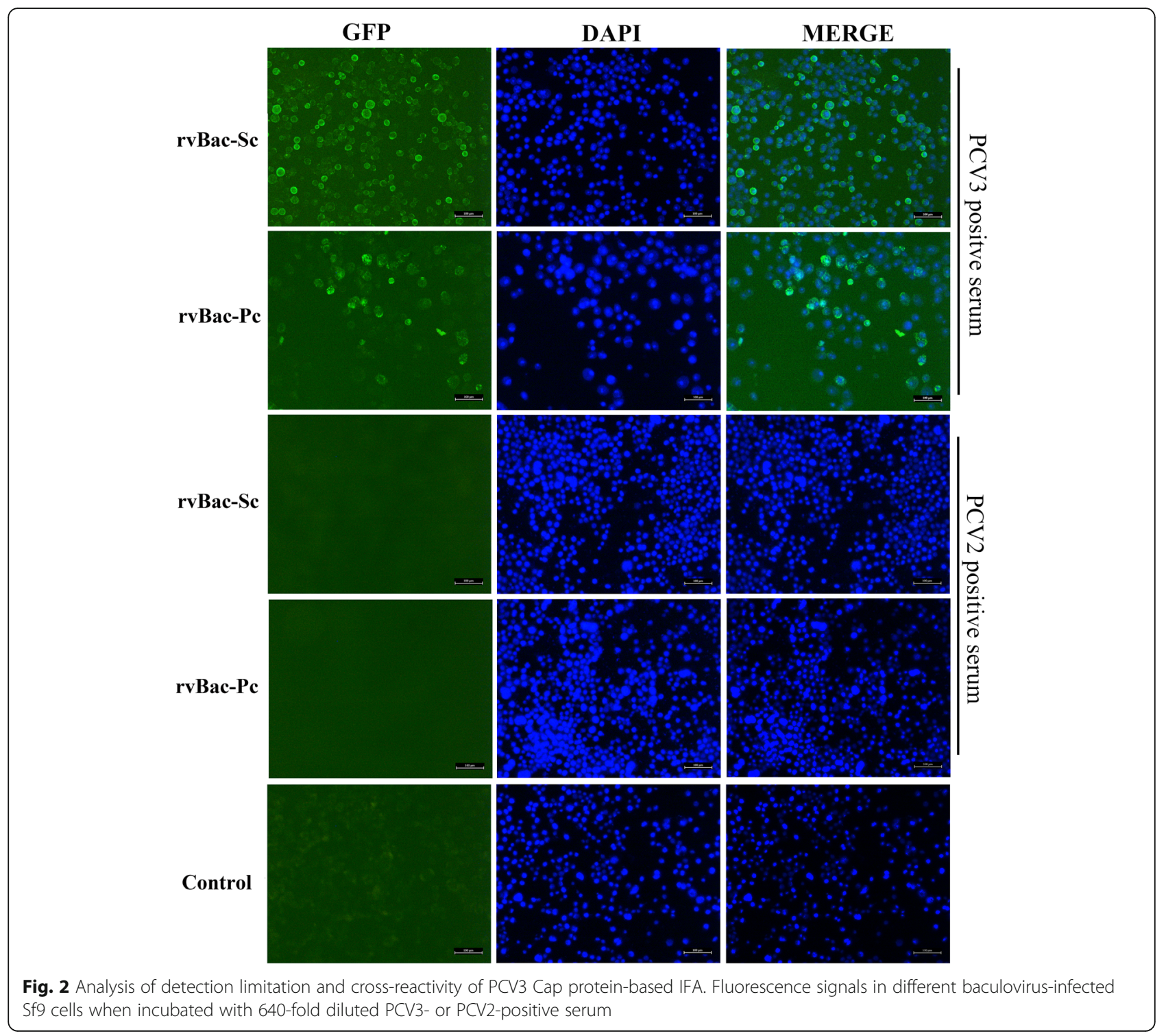

Fig. 2 Analysis of detection limitation and cross-reactivity of PCV3 Cap prote
Sf9 cells when incubated with 640-fold diluted PCV3- or PCV2-positive serum

Table 2 Results of PCV3 serum samples detected by IFA and ELISA

\begin{tabular}{|c|c|c|c|c|}
\hline \multirow{2}{*}{\multicolumn{2}{|c|}{$\begin{array}{l}\text { Paired Chi Square } \\
\text { Test }\end{array}$}} & \multicolumn{3}{|c|}{ ELISA } \\
\hline & & + & - & Total \\
\hline \multirow[t]{3}{*}{ IFA } & + & 46 & 0 & 46 \\
\hline & - & 3 & 53 & 56 \\
\hline & Total & 49 & 53 & 102 \\
\hline \multirow{2}{*}{\multicolumn{2}{|c|}{ Statistical results }} & \multicolumn{2}{|c|}{ Chi square value } & $p$ \\
\hline & & \multicolumn{2}{|l|}{86.87} & 0 \\
\hline
\end{tabular}

PCV3 Porcine circovirus type 3, IFA immunofluorescence assay summarized in Table 3. Our date indicated that PCV3 was widely spread in China.

In summary, this research developed an IFA method for the diagnosis and epidemiological investigation of PCV3. The epidemiological investigation of PCV3 in Hebei, Henan and Jiangxi, Chongqing of China was performed. This method can provide a reference for the development of commercial PCV3 antibody detection kit.

\section{Methods}

\section{Construction of the recombinant bacmid}

NLS sequence of PCV3 Cap protein (GenBank NO: KY354039) was predicted by NLStradamus (http:// www.moseslab.csb.utoronto.ca/NLStradamus). The Nterminal 33 amino acids were predicted as the NLS. Therefore, an insect gene codon-optimized ORF2 gene 
Table 3 Detection rates of PCV3 antibody

\begin{tabular}{|c|c|c|c|c|c|}
\hline \multirow[t]{2}{*}{ Background } & \multicolumn{5}{|c|}{ Growth stage } \\
\hline & Piglets & Nursery & Fattening & Sow & Total \\
\hline \multirow[t]{2}{*}{ PCV3 antibody positivity rate } & $33.33 \%$ & $37.31 \%$ & $37.62 \%$ & $59.35 \%$ & $45.83 \%$ \\
\hline & $7 / 21$ & $25 / 67$ & $38 / 101$ & $73 / 123$ & $143 / 312$ \\
\hline
\end{tabular}

was synthesized (GenScript Biotech Corp, Nanjing, China) and cloned into the pFastBac1 vector (Invitrogen, Thermo Fisher Scientific, Inc., Carlsbad, USA). For comparison, two Cap protein expression constructs were made: plasmid pFastBac1-ORF2 (Pc), containing a full-length ORF2 gene, and plasmid pFastBac1-ORF2 (Sc), containing the NLS-deleted ORF2 gene. Then, plasmids were transformed into DH10Bac competent cells. The positive bacmids, designated $\mathrm{rBac}-\mathrm{Sc}$ and $\mathrm{rBac}-\mathrm{Pc}$, respectively, were characterized by sequencing.

\section{Expression of recombinant protein}

The rBac-Sc, rBac-Pc and rBacmids (wild-type baculovirus) were transfected into Sf9 insect cells by using Lipofectamine $^{\mathrm{sm}} 2000$ (Life Technologies, CA, USA) and incubated for $4-5 \mathrm{~d}$ at $27^{\circ} \mathrm{C}$ to obtain recombinant baculoviruses. Supernatants of transfected cells were harvested as P1 generation viruses and designated rvBac-Sc, rvBac-Pc and rvBac, respectively. Subsequently, $50 \mu \mathrm{L}$ P1 generation virus was inoculated into a 6-well plate with fresh Sf9 cells and incubated for $72 \mathrm{~h}$ at $27^{\circ} \mathrm{C}$. After cells showed an apparent cytopathic effect (CPE), supernatant was collected as the second generation (P2) recombinant baculovirus. The virus was passaged as described above until the fourth generation (P4) and stored at $-80{ }^{\circ} \mathrm{C}$.

In total, $50 \mathrm{~mL} \mathrm{Sf9}$ cell suspension was infected with P4 generation virus at a multiplicity of infection (MOI) of 0.05 and incubated in a shaking incubator $(160 \mathrm{~g})$ at $27^{\circ} \mathrm{C}$ for $96 \mathrm{~h}$, after which the cells were collected for further analysis. Cap protein expression was analyzed by using a western blot assay with a PCV3-specific monoclonal antibody as previously described (Guo et al. 2016). Mouse anti-PCV3 Cap protein monoclonal antibody was used as the primary antibody, and HRP-goat anti-mouse IgG (AntGene, Wuhan, China) was used as the secondary antibody.

The expression and localization of PCV3 Cap protein in transfected cells was verified by IFA. P4 generation viruses of rvBac-Sc and rvBac-Pc, $1 \mu \mathrm{L}$ per well, were simultaneously inoculated into a 96-well plate with $2.0 \times 10^{4} \mathrm{Sf} 9$ cells/well. Sf9 cells inoculated with wild-type baculovirus were used as a negative control. IFA assay was performed as described previously (Woźniak et al. 2019).

\section{Determination of the optimal number of Sf9 cells and serum dilution}

Square array titration was used to determine the optimal number of cells for inoculation and serum dilution. Briefly, Sf9 cells were seeded in 96-well plates at $1.0 \times 10^{4}, 2.0 \times 10^{4}, 4.0 \times 10^{4}$ and $8.0 \times 10^{4} /$ well, and the P4 generation of rvBac-Sc, rvBac-Pc and rvBac was added at an MOI of 0.05 to the plates. After incubation for $96 \mathrm{~h}$ at $27^{\circ} \mathrm{C}$, cells were fixed and blocked as outlined above. The blocked plate was used immediately or stored at $-20{ }^{\circ} \mathrm{C}$. PCV3-positive serum and PCV3-negative serum were serially diluted to $1: 10,1: 20,1: 40,1: 80,1: 160,1: 320$ and $1: 640$. Then, $100 \mu \mathrm{L} /$ well of diluted sera was added to rvBac-Sc, rvBac-Pc and rvBac cell plates and incubated for $1 \mathrm{~h}$ at $37^{\circ} \mathrm{C}$. Afterwards, FITC-labeled goat anti-mouse secondary antibody (1:500) was added to the plate and then incubated at $37^{\circ} \mathrm{C}$ for $1 \mathrm{~h}$ in the dark. DAPI was used to stain nuclei. When a specific fluorescence signal was observed in cells infected with $\mathrm{rBac}-\mathrm{Sc}$ and rBac-Pc but not in the cells infected with control rBacmids, the sample was judged positive. According to the number of positive cells and intensity of fluorescence, the results were classified as,,,-++++++ , ++++ or +++++ .

\section{Detection limitation, cross-reactivity and repeatability of the IFA method}

Sf9 cells infected with rvBac-Sc, rvBac-Pc and rvBac were added to 96-well plates and subjected to IFA assay as described above. PCV3-positive serum was diluted to $1: 10,1: 20,1: 40,1: 80,1: 160,1: 320,1: 640,1: 1280$ and $1:$ 2560 , and then $100 \mu \mathrm{L} /$ well of the diluted serum was added to a 96-well plate to determine the detection limitation of IFA. Cross-reactivity was assessed by testing serum samples from pigs infected with PCV2, PRV, CSFV, and PRRSV. The same batch of positive and negative sera was used to stain different batches of cells to determine the repeatability of the assay.

\section{Sample collection}

A total of 312 pig serum samples from 21 farms in 4 provinces of China (Hebei, Henan, Jiangxi, and Chongqing) from January 2020 to March 2021 were kindly provide by Animal Disease Diagnostic Center of Huazhong Agricultural University. Samples were further categorized corresponding to the growth stage of pigs, 
including 21 serum samples from piglets, 67 serum samples from nursery pigs, 101 serum samples from fattening pigs, and 123 serum samples from breeder pigs. For serum collection, approximately $1.5 \mathrm{~mL}$ blood was transferred into $2 \mathrm{~mL}$ tubes (Fengqin, Guangzhou, China) and maintained at $4{ }^{\circ} \mathrm{C}$ for $24 \mathrm{~h}$. Then, samples were centrifuged for $10 \mathrm{~min}$ at $2000 \mathrm{~g}$ and $4^{\circ} \mathrm{C}$, supernatant was collected and stored at $-80^{\circ} \mathrm{C}$ for further study.

\section{Serological detection of PCV3 antibody by ELISA}

A total of 102 pig serum samples were randomly collected for ELISA analysis. Serum samples of PCV3specific Cap protein antibodies were evaluated according to a previous report (Wang et al. 2019). Briefly, PCV3 ORF2 gene fragment was inserted into pET-30a (Invitrogen, Thermo Fisher Scientific, Inc., Carlsbad, USA), and the recombinant protein was induced by $1 \mathrm{mmol} / \mathrm{L}$ IPTG (Sigma), followed by incubation at $37^{\circ} \mathrm{C}$ for $6 \mathrm{~h}$. The optimal antigen coating concentration was $1 \mu \mathrm{g} / \mathrm{mL}$, and serum dilution was $1: 20$. After incubation at $37^{\circ} \mathrm{C}$ for 1 $\mathrm{h}$, plate was washed with PBST (Chuntest) three times and incubated with $100 \mu \mathrm{L}$ goat anti-swine immunoglobulin G conjugated with horseradish peroxidase (Abclonal, Wuhan, China) for $1 \mathrm{~h}$ at $37^{\circ} \mathrm{C}$. After washing, a 2' 2-azino-bis-(3-ethylbenzothiazoline) substrate solution and then a $1.0 \%$ sodium dodecyl sulfate as a stop solution were added to all wells of the microplate. Serum samples were confirmed as positive if the absorbance was higher than the cutoff value (0.4).

\section{Statistical analysis}

Experimental results were analyzed by paired chi-square tests using SPSS V. 21.0. Pearson's correlation coefficient was calculated using the same software for determination of relative coupling efficiencies and comparison of singleplex versus multiplex assays.

\section{Acknowledgements}

Not applicable.

\section{Authors' contributions}

L.Y., C.L., J.W. and Y.C. contributed to the conception or design of the work, and the acquisition of data. X.Y. and A.H.M. completed the data analysis. Q.S., W.N., S.F., and Q.H. drafted the manuscript and revised it critically for important intellectual content. All authors have critically read and edited the manuscript.

\section{Funding}

This work was supported by a grant from the China Agriculture Research System (CARS-35).

\section{Availability of data and materials}

The datasets used and/or analyzed during the current study are available from the corresponding author on reasonable request.

\section{Declarations}

\section{Ethics approval and consent to participate}

All serum samples of pig that used in this research were kindly provide by Animal Disease Diagnostic Center of Huazhong Agricultural University.
Consent for publication

Not applicable.

\section{Competing interests}

The authors declare no conflict of interest.

\section{Author details}

${ }^{1}$ State Key Laboratory of Agricultural Microbiology, Huazhong Agricultural University, Wuhan, China. ${ }^{2}$ The Cooperative Innovation Center for Sustainable Pig Production, Huazhong Agricultural University, Wuhan, China. ${ }^{3}$ College of Veterinary Medicine, Huazhong Agricultural University, Wuhan, China.

Received: 28 April 2021 Accepted: 7 July 2021

Published online: 26 July 2021

\section{References}

Chen, G.H., K.J. Mai, L. Zhou, R.T. Wu, X.Y. Tang, J.L. Wu, L.L. He, T. Lan, Q.M. Xie, Y. Sun, and J.Y. Ma. 2017. Detection and genome sequencing of porcine Circovirus 3 in neonatal pigs with congenital tremors in South China. Transboundary and Emerging Diseases 64 (6): 1650-1654. https://doi.org/1 $0.1111 /$ tbed. 12702

Demir, T., S. Yalcin, and S. Kilic. 2020. Evaluation of the diagnostic performance and optimal cutoff value of a fourth-generation ELISA, VIDAS HIV-1/2 duo ultra assay, in a low-prevalence country. Diagnostic Microbiology and Infectious Disease 97 (1): 115011. https://doi.org/10.1016/j.diagmicrobio.202 0.115011.

Deng, J.H., X.D. Li, D.D. Zheng, Y.W. Wang, L.Y. Chen, H.H. Song, T.Y. Wang, Y.X. Huang, W.Q. Pang, and K.G. Tian. 2018. Establishment and application of an indirect ELISA for porcine Circovirus 3. Archives of Virology 163 (2): 479-482. https://doi.org/10.1007/s00705-017-3607-7.

Guo, X.Z., H. Hu, F.Z. Chen, Z.H. Li, S.Y. Ye, S. Cheng, M.J. Zhang, and Q.G. He. 2016. iTRAQ-based comparative proteomic analysis of Vero cells infected with virulent and CV777 vaccine strain-like strains of porcine epidemic diarrhea virus. Journal of Proteomics 130: 65-75. https://doi.org/10.1016/j. jprot.2015.09.002.

Guo, Z.H., H.Y. Ruan, S.L. Qiao, R.G. Deng, and G.P. Zhang. 2020. Co-infection status of porcine circoviruses $\left(\mathrm{PCV}_{2}\right.$ and $\left.\mathrm{PCV}_{3}\right)$ and porcine epidemic diarrhea virus (PEDV) in pigs with watery diarrhea in Henan Province, central China. Microbial Pathogenesis 142: 104047. https://doi.org/10.1016/..micpath.2020.1 04047

Jiang, H.J., D. Wang, J. Wang, S.S. Zhu, R.P. She, X.X. Ren, J.J. Tian, R. Quan, L. Hou, Z.X. Li, et al. 2018. Induction of porcine dermatitis and nephropathy syndrome in piglets by infection with porcine Circovirus type 3. Journal of Virology 93 (4): e02045-e02018. https://doi.org/10.1128/jvi.02045-18.

Kedkovid, R., Y. Woonwong, J. Arunorat, C. Sirisereewan, N. Sangpratum, M. Lumyai, S. Kesdangsakonwut, K. Teankum, S. Jittimanee, and R. Thanawongnuwech. 2018. Porcine Circovirus type 3 (PCV3) infection in grower pigs from a Thai farm suffering from porcine respiratory disease complex (PRDC). Veterinary Microbiology 215: 71-76. https://doi.org/10.1016/j. vetmic.2018.01.004

Koh, G.C.K.W., D.H. Paris, S.D. Blacksell, R.J. Maude, and P.N. Newton. 2010 Diagnosis of scrub typhus. The American Journal of Tropical Medicine and Hygiene 82 (3): 368-370. https://doi.org/10.4269/ajtmh.2010.09-0233.

Ku, X., F. Chen, P. Li, Y. Wang, X. Yu, S. Fan, P. Qian, M. Wu, and Q. He. 2017. Identification and genetic characterization of porcine Circovirus type 3 in China. Transboundary and Emerging Diseases 64 (3): 703-708. https://doi.org/1 0.1111/tbed.12638.

Kwon, T., S.J. Yoo, C.K. Park, and Y.S. Lyoo. 2017. Prevalence of novel porcine Circovirus 3 in Korean pig populations. Veterinary Microbiology 207: 178-180. https://doi.org/10.1016/j.vetmic.2017.06.013.

Li, X.D., Y.L. Bai, H.Y. Zhang, D.D. Zheng, T.Y. Wang, Y.W. Wang, J.H. Deng, Z. Sun, and K.G. Tian. 2018. Production of a monoclonal antibody against porcine Circovirus type 3 cap protein. Journal of Virological Methods 261: 10-13. https://doi.org/10.1016/j.jviromet.2018.07.014.

Palinski, R., P. Piñeyro, P.C. Shang, F.F. Yuan, R. Guo, Y. Fang, E. Byers, and B.M. Hause. 2017. A novel porcine Circovirus distantly related to known circoviruses is associated with porcine dermatitis and nephropathy syndrome and reproductive failure. Journal of Virology 91 (1): 01879-01816. https://doi. org/10.1128/jvi.01879-16.

Phan, T.G., F. Giannitti, S. Rossow, D. Marthaler, T.P. Knutson, L.L. Li, X.T. Deng, T. Resende, F. Vannucci, and E. Delwart. 2016. Detection of a novel Circovirus 
PCV3 in pigs with cardiac and multi-systemic inflammation. Virology Journal 13 (1): 184. https://doi.org/10.1186/s12985-016-0642-z.

Racine, S., A. Kheyar, C.A. Gagnon, B. Charbonneau, and S. Dea. 2004. Eucaryotic expression of the nucleocapsid protein gene of porcine Circovirus type 2 and use of the protein in an indirect immunofluorescence assay for serological diagnosis of postweaning multisystemic wasting syndrome in pigs. Clinical and Diagnostic Laboratory Immunology 11 (4): 736-741. https://doi.org/10.112 8/CDLI.11.4.736-741.2004.

Saraiva, G.L., P.M.P. Vidigal, J.L.R. Fietto, G.C. Bressan, A. Silva Júnior, and M.R. Almeida. 2018. Evolutionary analysis of porcine Circovirus 3 (PCV3) indicates an ancient origin for its current strains and a worldwide dispersion. Virus Genes 54 (3): 376-384. https://doi.org/10.1007/s11262-018-1545-4.

Taber, L.H., F. Brasier, R.B. Couch, S.B. Greenberg, D. Jones, and V. Knight. 1976 Diagnosis of herpes simplex virus infection by immunofluorescence. Journal of Clinical Microbiology 3 (3): 309-312. https://doi.org/10.1128/jcm.3.3.309-312.1 976.

Wang, J., F. Chen, X. Ku, C. Li, and Q. He. 2019. Establishment and clinical application of an indirect ELISA for detection of antibodies against PCV3 based on recombinant ORF2 protein. Chinese Journal of Animal and Veterinary Sciences. 50 (2): 454-460

Wen, S., W. Sun, Z. Li, X. Zhuang, G. Zhao, C. Xie, M. Zheng, J. Jing, P. Xiao, M. Wang, J. Han, J. Ren, H. Liu, H. Lu, and N. Jin. 2018. The detection of porcine Circovirus 3 in Guangxi, China. Transboundary and Emerging Diseases 65 (1): 27-31. https://doi.org/10.1111/tbed.12754.

Woźniak, A., D. Miłek, P. Bąska, and T. Stadejek. 2019. Does porcine Circovirus type 3 (PCV3) interfere with porcine Circovirus type 2 (PCV2) vaccine efficacy? Transboundary and Emerging Diseases 66 (4): 1454-1461. https://doi.org/1 $0.1111 /$ tbed.13221.

Xu, P.L., Y. Zhang, Y. Zhao, H.H. Zheng, H.Y. Han, H.X. Zhang, H.Y. Chen, M.F. Yang, and L.L. Zheng. 2018. Detection and phylogenetic analysis of porcine Circovirus type 3 in central China. Transboundary and Emerging Diseases 65 (5): 1163-1169. https://doi.org/10.1111/tbed.12920.

Yuan, L., Y.Y. Liu, Y.N. Chen, X.X. Gu, H. Dong, S. Zhang, T. Han, Z. Zhou, X.H. Song, and C.B. Wang. 2020. Optimized real-time fluorescence PCR assay for the detection of porcine Circovirus type 3 (PCV3). BMC Veterinary Research 16 (1): 249. https://doi.org/10.1186/s12917-020-02435-y.

Zhang, J.X., Z.G. Liu, Y.W. Zou, N. Zhang, D.L. Wang, D. Tu, L.C. Yang, Z.B. Deng, Y. Yang, P. Jiang, et al. 2018. First molecular detection of porcine Circovirus type 3 in dogs in China. Virus Genes 54 (1): 140-144. https://doi.org/10.1007/s112 62-017-1509-0

Zhang, S.J., D.L. Wang, Y.F. Jiang, Z.M. Li, Y.W. Zou, M. Li, H.Y. Yu, K. Huang, Y. Yang, and N.D. Wang. 2019. Development and application of a baculovirusexpressed capsid protein-based indirect ELISA for detection of porcine Circovirus 3 lgG antibodies. BMC Veterinary Research 15 (1): 79. https://doi. org/10.1186/s12917-019-1810-3.

Zheng, S., X. Wu, L. Zhang, C. Xin, Y. Liu, J. Shi, Z. Peng, S. Xu, F. Fu, J. Yu, W. Sun, S. Xu, J. Li, and J. Wang. 2017. The occurrence of porcine Circovirus 3 without clinical infection signs in Shandong Province. Transboundary and Emerging Diseases 64 (5): 1337-1341. https://doi.org/10.1111/tbed.12667.

\section{Publisher's Note}

Springer Nature remains neutral with regard to jurisdictional claims in published maps and institutional affiliations.

Ready to submit your research? Choose BMC and benefit from:

- fast, convenient online submission

- thorough peer review by experienced researchers in your field

- rapid publication on acceptance

- support for research data, including large and complex data types

- gold Open Access which fosters wider collaboration and increased citations

- maximum visibility for your research: over $100 \mathrm{M}$ website views per year

At $\mathrm{BMC}$, research is always in progress.

Learn more biomedcentral.com/submissions 